\title{
PERCEPÇÃO DO TRABALHO DOCENTE EM UMA UNIVERSIDADE DA REGIÃO NORTE DO BRASIL
}

\author{
PERCEPTION OF THE TEACHING PROFESSION AT A UNIVERSITY IN NORTHERN BRAZIL
}

PERCEPCIÓN DE LA LABOR DOCENTE EN UNA UNIVERSIDAD DE LA REGIÓN NORTE DE BRASIL

\author{
Rozilaine Redi Lago ${ }^{1}$ \\ Bruna Souza Cunha ${ }^{2}$ \\ Maria Fernanda de Sousa Oliveira Borges ${ }^{3}$
}

Resumo Buscou-se conhecer a percepção da experiência do trabalho docente em cursos de saúde de uma universidade federal da região Norte do Brasil. Utilizando-se abordagem qualitativa, foram entrevistados seis docentes de cursos de saúde dessa universidade, cujos dados foram submetidos à análise de conteúdo. Predominaram mulheres na função docente, e a valorização dessa função como vínculo estável de trabalho, fonte de rendimentos e função social. No trabalho docente, a maioria se concentra no desenvolvimento de habilidades técnico-científicas dos alunos, expressando a necessidade da qualificação contínua e apoio institucional insuficiente. As relações pessoais desses docentes com alunos e outros professores e técnico-administrativos são reconhecidamente mediadoras da qualidade do processo de ensino-aprendizagem e trabalho. Quanto à saúde, a maior parte se sente vulnerável e desgastada, principalmente em aspectos psicoemocionais, o que influencia as suas relações sociais dentro e fora do ambiente de trabalho. Embora o exercício profissional tenha sido identificado como fonte de estabilidade, realização pessoal e financeira, destacam-se a precariedade e a sobrecarga de trabalho, que tendem a induzir sofrimento e adoecimento. Esta reflexão entre docentes, movimentos sindicais e instituições de ensino pode subsidiar ajustes institucionais, legais, curriculares e sociais para melhorar o processo de ensino-aprendizagem e a qualidade de vida dos docentes.

Palavras-chave docente; saúde do trabalhador; recursos humanos em saúde.

\begin{abstract}
An attempt was made to get to know the views professors have on the experience of teaching in health courses at a federal university located in northern Brazil. Using a qualitative approach, six professors working at the university's health courses were interviewed, and their data were subjected to content analysis. Most professors were female, and the role was valued as it represents a stable employment status, a source of income, and a social function. In the teaching activity, most focus on developing the students' technical and scientific skills, expressing the need for ongoing training and insufficient institutional support. Personal relationships among these professors and students and with other professors and technical administrators are known to mediate the quality of the teaching/learning and work processes. Insofar as health is concerned, most feel vulnerable and worn, particularly in psycho-emotional aspects, a fact that influences their social relations within and outside of the workplace. Although the professional practice has been identified as a source of stability and of personal and financial realization, the precariousness and work overload stand out and tend to induce suffering and illness. This reflection among professors, labor union movements, and educational institutions may support institutional, legal, curriculum and social adjustments in order to improve the process of teaching and learning and the professors' quality of life.
\end{abstract}

Keywords professor; occupational health; human resources in health. 


\section{Introdução}

A saúde do trabalhador pode ser entendida como a vigilância e o manejo dos riscos à saúde do trabalhador decorrentes do processo de trabalho, neles incluídos os riscos psicossociais, químicos, biológicos e físicos, condições ergonômicas adversas e alergias, além de uma complexa rede de acidentes e insegurança. O trabalho desenvolvido e a natureza do trabalho têm importantes influências na saúde do trabalhador. O primeiro esforço mundial na área de saúde do trabalhador foi empreendido pela Organização Mundial de Saúde (OMS) em 1950, com a criação do Comitê Ocupacional, em conjunto com a Organização Internacional do Trabalho (OIT), cujo trabalho colaborativo persiste até os dias atuais (World Health Organization, 2010).

São abundantes as evidências que respaldam as repercussões positivas que o investimento nos recursos humanos em saúde têm sobre os indicadores de saúde da população, tornando imprescindível uma cooperação múltipla de países e sociedade visando à valorização, aperfeiçoamento e difusão dessa classe de trabalho, especialmente em países cujo déficit desses profissionais persiste (Organización Mundial de la Salud, 2006).

No elenco de ocupações laborais na área da saúde, podem-se destacar os agentes educacionais, atuantes em instituições de ensino superior. Esses agentes exercem atividades tanto no ambiente acadêmico quanto nos ambientes dos diversos serviços de saúde, sobrepondo-se ao trabalho desempenhado pelos demais profissionais de saúde. Os profissionais docentes diretamente envolvidos com a formação profissional na área da saúde historicamente têm demonstrado o impacto de sua atuação, ao influenciarem o delineamento de políticas de Estado na área da saúde, bem como as transformações sociais (Campos, 2006).

No setor da educação, o processo de reestruturação produtiva gera novas demandas que implicam transformações na organização social do trabalho docente. A exigência de níveis cada vez mais elevados de escolarização desses profissionais para se inserirem no mercado de trabalho geralmente é desproporcional à qualidade das condições de trabalho vivenciadas. Em concorrência com o atendimento a novas demandas da organização mercadológica dos sistemas de produção, encontra-se o alto padrão de exigência de competências e habilidades diversificadas entre os profissionais docentes. No Brasil, o descompasso no desenvolvimento das atividades de ensino em contextos desestruturados gera uma sobrecarga de trabalho para esses profissionais (Brum et al., 2012).

O trabalho docente apresenta grandes exigências intelectuais e psicoemocionais, e habilidades sociais e pedagógicas. A investigação do estresse no trabalho de alta exigência resultante de relações entre demanda psicológica e controle, tal como experimentado por essa parcela de trabalhadores, 
associa-se a repercussões negativas sobre a saúde e o processo de trabalho (Theorel, 2000; Alves et al., 2009; Vedovato e Monteiro, 2008).

Conferindo as queixas relacionadas ao trabalho em grupos de profissionais docentes, podemos destacar a contribuição de Macedo: “Queixas relativas à saúde têm sido mais frequentemente associadas a problemas no trabalho do que a qualquer outro aspecto da vida, incluindo problemas financeiros ou familiares" (Macedo, 2007, p. 2.327).

O sofrimento desse trabalhador se reflete no seu cotidiano familiar e na equipe de trabalho, com repercussões na produtividade do trabalho coletivo. Nesse sentido, cabe às autoridades administrativas institucionais - tanto no âmbito da universidade quanto no do Ministério da Educação, bem como nas respectivas organizações sociais, programarem ações para o alcance da realização pessoal e profissional, proporcionadas por meio da priorização da qualidade de vida no processo de trabalho (Barreto, 2008).

A docência é uma profissão em expansão, por vezes revestida de percepções de voluntariado, 'vocação' e 'missão'. Essas percepções podem interferir negativamente no processo de empoderamento e valorização social desses profissionais. Ademais, as configurações sociais e familiares contemporâneas geram novas demandas por parte dos alunos, demandas que exigem inovadoras metodologias de ensino-aprendizagem. Os docentes, diante das pressões sociais, institucionais e discentes, experimentam grande dificuldade para acompanhar e responder efetivamente a essas demandas (Batista et al., 2005).

Ao estudar a 'condição docente', Teixeira (2007) revela pontos críticos, na dimensão social e da saúde, que demonstram uma situação de desvantagem experimentada por essa categoria profissional. Outros autores confirmam em seus estudos que professores têm maior risco de sofrimento psíquico de diferenciados matizes e maior prevalência de transtornos psíquicos menores quando comparados a outros grupos populacionais (Gasparini, Barreto e Assunção, 2005).

Zaragoza (1999) designou como 'mal-estar docente' a sensação de mal-estar difuso percebida por esses profissionais e elaborou um modelo de explicação que considera que determinada combinação de fatores pode conduzir os professores a um estado de ansiedade, denominado 'esgotamento docente', que também afeta a personalidade.

Raros são os estudos comparados desenvolvidos na América Latina no campo da profissão docente para descobrir outras dimensões relativas aos professores e ao trabalho docente, tais como autopercepção da condição docente, concepções sobre os alunos e colegas de trabalho com os quais o profissional convive, posição que ocupa na estrutura social, formação, condições de trabalho, política educativa, salário, valores e consumos culturais (Duran, 2008). 
Considerando a necessidade de pesquisas que abordem a condição docente nos cursos de formação na área de saúde de instituições federais de ensino superior (Ifes) na região Norte do Brasil, buscou-se conhecer a percepção da experiência do trabalho docente em cursos de saúde de uma universidade federal dessa região, por meio da descrição de aspectos do processo de ensino-aprendizagem utilizado, inter-relações pessoais neste ambiente, expectativas sobre a carreira profissional, concepções acerca do papel docente, facilidades e dificuldades experimentadas no processo de trabalho, bem como mudanças na qualidade de vida e saúde dos próprios sujeitos. Essas informações podem subsidiar ajustes institucionais, movimentos sindicais e outros mecanismos de reflexão-ação que tenham o potencial de desencadear mudanças nos elementos componentes do exercício docente.

\section{Delineamento, amostragem, população de estudo e coleta de dados}

Trata-se de um estudo exploratório-descritivo, de abordagem qualitativa (Creswell, 2007). As unidades de observação foram professores dos cursos de graduação da área da saúde de uma Ifes localizada na região Norte do Brasil. A amostragem foi feita por conveniência, após convite aberto dirigido a professores do órgão que aglutinava o conjunto de cursos de saúde da instituição lócus da pesquisa, composto pelos cursos de bacharelado em Enfermagem, Medicina, Nutrição, Educação Física e Saúde Coletiva. Em seguida, deu-se prioridade no convite pessoal para os sujeitos que tivessem facilidade de comunicação, demonstrassem envolvimento e compreensão da relevância do problema de pesquisa e aceitassem participar dela como sujeitos de pesquisa.

A seleção reuniu seis docentes voluntários: dois professores do curso de bacharelado em Saúde Coletiva, dois professores do curso de bacharelado em Enfermagem, um professor do curso de bacharelado em Nutrição e um professor do curso de bacharelado em Educação Física. A delimitação do número de sujeitos participantes da pesquisa obedeceu a critérios de saturação teórica dos dados. Nenhum professor do curso de Medicina manifestou interesse em participar deste estudo.

Os docentes foram submetidos à entrevista individual segundo um roteiro com perguntas norteadoras, aplicada por uma das pesquisadoras durante o primeiro semestre de 2011.

\section{Instrumento de aferição e variáveis}

O instrumento de coleta de dados foi composto por um roteiro contendo questões norteadoras abertas, baseadas no conteúdo de discussões da cate- 
goria docente em foros colegiados institucionais e de representações sindicais, observação assistemática dos cenários de exercício docente na instituição e informações levantadas na revisão de literatura sobre o assunto. $\mathrm{O}$ roteiro foi revisado e aplicado previamente em docentes não participantes da pesquisa, para testar o vocabulário utilizado, a sensibilidade das respostas e a habilidade do entrevistador.

Durante a entrevista, foram introduzidas as seguintes perguntas: Quais eram suas expectativas em relação ao exercício docente? Elas estão sendo alcançadas? Qual é o papel do docente de cursos de saúde na Ifes? Quais foram as mudanças experimentadas em sua qualidade de vida e saúde após o ingresso na carreira docente, nos seguintes aspectos: socioeconômico, psicoemocional, espiritual, dentre outros? Quais são as estratégias de ensino-aprendizagem utilizadas? Como é a sua inter-relação com discentes e com outros profissionais? Quais são as dificuldades e facilidades encontradas durante o exercício docente no âmbito da Ifes? Os docentes puderam apresentar sugestões de possíveis ajustes institucionais com base nas dificuldades vivenciadas. De forma complementar, ao final da entrevista os sujeitos responderam a questões fechadas sobre aspectos socioeconômicos e demográficos como: sexo, idade, status conjugal, naturalidade, habitação, renda e nível educacional.

O local de realização da entrevista foi o ambiente privado de sala de aula ou a sala de professores, em horário previamente agendado, obedecendo à preferência do entrevistado. As entrevistas foram gravadas utilizando-se um gravador digital e tiveram duração média de 30 minutos.

\section{Processamento e análise dos dados}

Para a análise de dados, seguiram-se os seguintes passos: gravação das entrevistas, transcrição e análise de dados de acordo com as técnicas de análise de conteúdo e discurso conforme Caregnato e Mutti (2006), respectiva codificação dos mesmos, estabelecimento de eixos ou pontos principais das falas, categorização e comparação. Os dados foram representados em excertos de textos intercalados com os respectivos comentários. Para os dados socioeconômicos e demográficos, a criação, a alimentação e a correção do banco de dados foram efetuadas utilizando-se o programa Excel, por meio do qual foram calculadas frequências absolutas e relativas.

A codificação dos dados qualitativos seguiu a legenda: PE (professor de Enfermagem); PSC (professor de Saúde Coletiva), PEF (professor de Educação Física) e PN (professor de Nutrição), acrescentando-se um número para diferenciação de professores de um mesmo curso.

A validação interna dos dados foi feita por intermédio da conferência dos sujeitos de pesquisa sobre a significação dada pelas autoras aos excertos de 
texto selecionados. Como recurso alternativo de validação interna, a análise de dados foi efetuada por duas pesquisadoras, em momentos diferentes, para escolha da versão final apresentada nos resultados e discussão.

Os indivíduos que concordaram, voluntariamente, em participar do estudo assinaram o termo de consentimento livre e esclarecido, atendendo aos critérios éticos estabelecidos pela resolução Conep n. 196/1996. Esta pesquisa foi, previamente, aprovada pelo Comitê de Ética em Pesquisa da Ifes objeto de estudo.

\section{Aspectos socioeconômicos e demográficos}

Os docentes pesquisados em sua maioria eram mulheres $(4 ; 66,5 \%)$, casadas $(4 ; 66,5 \%)$, residentes em casa ou apartamento próprio $(4 ; 66,5 \%)$, com idade entre 26 e 40 anos, naturais de outros estados do território brasileiro $(5 ; 73 \%)$, com escolaridade máxima entre especialista $(2 ; 33,3 \%)$, mestrado $(2 ; 33,3 \%)$ e doutorado $(2 ; 33,3 \%)$, com renda familiar média variando de acordo com a titulação e tempo de carreira, superior a 7 salários mínimos (2; 33,5\%), para os titulados como doutores, e entre 4 e 7 salários mínimos para os demais $(4 ; 66,5 \%)$.

Houve predominância do sexo feminino entre os sujeitos da pesquisa, refletindo a distribuição de sexo na população de origem, os docentes de cursos de saúde do Ifes ( $64 \%$ do total de 121 docentes são do sexo feminino). O predomínio do sexo feminino no universo da docência é um fenômeno cadenciado por questões históricas e sociais da posição da mulher na sociedade, segundo achados de Cardoso et al. (2011). Apesar da inserção no mercado de trabalho externo ao domicílio, a mulher, em geral, acumula o trabalho familiar interno (cuidado geral de casa, dos filhos, das refeições etc.), circunstância pela qual as mulheres relatam maior estresse e desgaste físico relacionado ao trabalho, configurando-se uma questão de gênero importante, discutida por outros pesquisadores, também identificada neste estudo (Souza e Brito, 2012).

No aspecto socioeconômico, em relação a outras esferas do governo ou docentes de outros níveis de ensino (fundamental, médio e infantil), a remuneração do docente dos Ifes é mais alta. Entretanto, em relação a outras funções públicas federais, essa função, que geralmente apresenta o maior nível de formação acadêmica de seus profissionais, é uma das de menor remuneração ou pior plano de cargo, carreiras e salários, situação que tem gerado muitos movimentos sociais grevistas ao longo da história no Brasil, inclusive nos últimos anos (Sindicato Nacional dos Docentes das Instituições de Ensino Superior, 2012). 


\section{Ensino-aprendizagem: um processo de 'exposição' e 'discussão'}

Os sujeitos relataram, principalmente, o uso de técnicas de exposição de conteúdo vinculadas à abordagem tradicional de ensino-aprendizagem; em segundo plano, foram apresentadas abordagens alternativas de ensino-aprendizagem envolvendo atividades práticas, como estágios, atividades lúdicas, seminários e rodas de conversas, entre outras, as quais correspondem a metodologias mais ativas no processo educativo, sendo frequentemente mencionada a expressão 'discussão' para descrevê-las, como mostram as falas dos sujeitos:

Utilizo filmes, rodas de conversa e algumas atividades, como colagem/desenhos, mas na maioria das vezes permaneço com o método tradicional de aula expositiva (PSCl).

Aulas expositivas, slides, seminários e debates (PSC2).

Primeiramente, a exposição do conteúdo teórico. Utilizo slides, debates, seminários; uso de metodologias dinâmicas que facilitem a comunicação com o aluno e seu aprendizado (PEl).

Pesquisas acerca dos temas, discussão para aprimoramento e divisão dos conhecimentos e aulas práticas (PE2).

Aplicação dos conteúdos nas práticas com os alunos (PN).

Para mim a melhor metodologia é a que utiliza diversas formas de explicação para fixar o conteúdo: proponho discussões, seminários e principalmente a utilização da prática (PEF).

Tal predominância da abordagem tradicional de ensino é corroborada pela descrição feita por Cotta et al. (2002). ao estudarem a conjugação de métodos tradicionais com metodologias ativas entre graduandos de cursos de saúde de uma universidade pública brasileira: “Os profissionais de saúde têm recebido uma formação baseada em metodologias de ensino-aprendizagem conservadoras, sofrendo forte influência da fragmentação e reducionismo" (Cotta et al., 2012, p. 788).

Rozendo et al. (1999) observam a predominância da habilidade técnica e uma lacuna na habilidade didático-pedagógica entre professores universitários da área de saúde. Essas incongruências existiam desde o processo de contratação de professores e continuavam durante o exercício da docência, 
sendo também mediadas pela crença de que alunos universitários, adultos, aprovados por meio de um rigoroso processo seletivo de avaliação de conhecimento, já estariam habilitados a 'aprender sozinhos'.

Além disso, em estudos do aproveitamento de metodologias ativas em comparação com a abordagem tradicional de ensino, diferentes autores constataram a aceitação e a percepção positiva dos alunos quanto à qualidade da aprendizagem proporcionada pelas metodologias ativas de ensino-aprendizagem, favorecendo a integração entre conhecimentos anteriores e atuais, aprendizagem significativa, aprendizagem colaborativa - envolvendo processos de cooperação entre pequenos grupos de trabalho -, liberdade de expressão e desenvolvimento de habilidades pessoais (Cotta et al., 2012; Torres, Alcantara e Irala, 2004).

\section{Relação discente-docente: um 'campo minado' permeado por aceitação, (i)maturidade e avaliação}

Quanto às dificuldades enfrentadas no relacionamento com os alunos, os docentes acreditam que elas ocorrem em virtude do momento de vida experimentado pelos discentes permeado pelo conflito entre a autonomia conquistada com o ingresso na faculdade e as exigências dessa nova fase superiores às do ensino médio (tipo de metodologia de ensino, complexidade de conteúdos, dependência dos pais). Por estarem majoritariamente no final da adolescência, os discentes apresentam inseguranças e dúvidas.

Para os docentes, questões como necessidade do estudante em apresentar um rendimento escolar suficiente, manter a atenção na formação - em concorrência com outros interesses, como relacionamentos afetivos com outros colegas e namoro - e ser avaliado, periodicamente, pelo professor podem gerar dificuldades na relação docente-discente. Os docentes dirigiram a origem das dificuldades nessa relação para os comportamentos dos discentes:

Os alunos estão vindo da adolescência, do ensino médio, com outra visão, quando você tem que formar novos conceitos; (...) no início algumas atitudes minhas, nas primeiras disciplinas (...), podem chocar, mas depois eles se acostumam, entendem, criam vínculos (PSCl).

Sempre tem um grupo, ou determinados alunos, que ficam dispersos das aulas; eu precisei chamar a atenção de um aluno; ele não aceitou e iniciou uma discussão por eu pedir sua retirada da sala (PEF).

Uma aluna discordou da nota que eu dei a ela em práticas; embora eu tendo explicado os parâmetros para a avaliação, em comparação com os demais alunos, 
no aspecto físico, vestimenta, postura etc. (...). No entanto, ela continuou a se apresentar de forma incoerente e, no final, a nota dela continuou baixa (PE1).

As crenças de professores a respeito das competências/habilidades dos estudantes nas relações interpessoais e sua associação com o desenvolvimento socioemocional e intelectual dos alunos interferem no processo de ensino-aprendizagem, podendo facilitá-lo, caso o professor as considere, ou servir de barreira, caso o professor subestime o desempenho do aluno (Paiva e Del Prette, 2009).

De acordo com Sgariboldi, Puggina e Silva (2011), a relação docente-discente, além de muitos outros aspectos pessoais e institucionais, é mediadora do processo de ensino-aprendizagem e depende de características como a habilidade de comunicar-se, sensibilidade e percepção do outro, preparo, tanto acadêmico-científico quanto didático-pedagógico, experiência de serviço, dentre outros aspectos do professor para promover a facilitação dessa inter-relação. Além desses fatores, é preciso promover um ambiente de motivação, porque ela "é uma condição interna do indivíduo e, no aprendizado, os sentimentos, as relações interpessoais, a afetividade, as diferenças culturais, as crenças e os valores estão envolvidos" (Sgariboldi, Puggina e Silva, 2011, p. 1207).

\section{Prática profissional docente: autonomia criativa diante da falta de estrutura}

Os aspectos mencionados como facilitadores da docência na universidade foram: autonomia criativa para exercer a docência (liberdade para o planejamento das aulas na escolha de estratégias de ensino), oportunidades de continuação da formação acadêmica, estabilidade do vínculo de trabalho e a possibilidade de relacionar-se com os alunos e outros professores, conforme ilustram as falas a seguir:

Aprendizagem e oportunidade de conviver com alunos e outros profissionais (PSCl).

Como professor tenho plena autonomia, tenho uma ementa para seguir, mas como docente, faço e planejo minhas aulas conforme eu queira, dentro da minha visão (...). Os alunos fazem festa de aniversário, convidam pra churrasco etc. (PSC2).

Estabilidade financeira (PEl).

Troca de conhecimentos que ocorre na prática profissional e, claro, não esquecendo que minha docência me garante estabilidade financeira (PE2). 
Aprendizado e a autonomia da didática (...) (PN).

Relação com os alunos, oportunidade de qualificação profissional, alcançando o mestrado e até o doutorado (PEF).

Por outra parte, os docentes destacaram como dificuldades de sua prática, principalmente, a falta de estrutura física (incluindo laboratórios, materiais e equipamentos), recursos humanos insuficientes, sobrecarga de trabalho, estrutura técnico-científica defasada e falta de compartilhamento de decisões técnico-administrativas institucionais com a categoria docente. Um docente mencionou como dificuldade do exercício docente as lacunas trazidas da formação anterior, as quais geram necessidade de aperfeiçoamento:

Necessidade de aprofundamento em conteúdos específicos da minha área de ensino (PSCl).

Número adequado de professores, pois a gente acaba ficando sobrecarregado de coisas, tendo que assumir compromissos extras, (...) falta de material, distanciamento da equipe central da universidade dos centros [de ensino] (PSC2).

Falta de estrutura, falta de internet (...). Espaço físico, salas [de professores] apertadas e úmidas, com vários professores; número inadequado de profissionais e investimentos em fóruns, encontros nacionais. (...) O estudo [preparo de aulas] e pesquisas ficam restritos devido ao curto tempo para planejamento e ministração de aulas (PEl).

Faltam laboratórios, salas confortáveis, estrutura. Acabamos ficando sobrecarregados e não há tempo para pesquisas, trabalhos de intercâmbio e outras atividades de preparo (PE2).

Escassez de laboratórios para as aulas práticas e biblioteca para pesquisa, assim os alunos não buscam em livros, em referenciais fidedignos e apelam para a internet (PEF).

Observa-se que a formação dos docentes enfatiza habilidades técnicas; no entanto, muitos deles, quando confrontados com o contexto de ensino-aprendizagem em sala de aula, têm buscado desenvolver as habilidades didático-pedagógicas. Como são escassas as iniciativas institucionais a esse respeito, os professores, ao mesmo tempo, sentem-se autônomos - pela liberdade de escolha da configuração de suas próprias estratégias de ensino junto aos alunos - e limitados - pela falta de apoio institucional, tanto do ponto de vista físico-estrutural quanto do desenvolvimento da formação 
profissional dentro da universidade, a qual é estimulada muito mais no aspecto da produção científica, expresso em quantidade de publicações, do que na qualidade e aproveitamento do ensino (Rozendo et al., 1999; Sgariboldi, Puggina e Silva, 2011).

Essas inadequações, assim como outras limitações inerentes à função docente, enquanto categoria laboral no elenco do funcionalismo público federal brasileiro, em comparação com outras funções desse âmbito, têm despertado movimentos sociais trabalhistas por parte dos docentes, tais como o movimento grevista recentemente empreendido, que perdurou por mais de noventa dias e não alcançou a negociação pretendida (Sindicato Nacional dos Docentes das Instituições de Ensino Superior, 2012).

Por sua vez, quando se compara a valorização da função docente no âmbito universitário, tanto na percepção do imaginário social quanto nos planos de cargos, carreiras e salários, aos docentes vinculados a outras esferas de governo e outros níveis de ensino, o docente universitário encontra-se em vantagem, motivo pelo qual os relatos são positivos, para a maioria dos sujeitos desta pesquisa, no aspecto da remuneração e estabilidade alcançadas por meio do vínculo atual de trabalho.

A estabilidade do vínculo de trabalho reportada por docentes de Ifes tem cobrado um 'alto preço' para a qualidade de vida dos mesmos, envolvendo um trabalho de alta exigência, com ampla diversidade de atividades, horas trabalhadas excedentes à jornada semanal, invasão do universo privado e do tempo de repouso pelo trabalho, cobranças por produtividade quantitativa, dificuldades na aferição concreta das atividades desempenhadas e respectiva visualização dessas pela administração institucional superior (Borsoi, 2012).

\section{A docência pretendida: um trabalho de ensino e aprendizagem, com estabilidade de trabalho e financeira}

A carreira docente em uma universidade federal foi vista pelos sujeitos como possibilidade de trabalho estável, de qualificação profissional e de contribuir para a formação de outros sujeitos - compartilhamento de conhecimentos e realização de desejo/sonho pessoal. Quanto ao alcance das expectativas profissionais, prevaleceu entre os docentes a satisfação parcial/total delas, conforme os seguintes relatos:

Oportunidade de continuar os meus estudos e transmitir um sentimento e um conhecimento político de forma técnica, (...) com estabilidade no emprego. Todas as minhas expectativas estão sendo alcançadas, pois tenho a oportunidade de cursar um mestrado, de transmitir um conhecimento que foi adquirido mediante 
a [minha] experiência profissional como gestora de sistemas e serviços de saúde (PSC1).

A intenção era trilhar uma carreira acadêmica. (...) estou muito satisfeito com o meu trabalho (PSC2).

Quando eu sonhei em ser professora, eu me imaginava envolvida em pesquisas, tendo tempo para estudar, me dedicar às aulas. (...) quando eu me formei já percebia e queria esta profissão e dividir conhecimentos (PEl).

As minhas expectativas eram em relação à disseminação do conhecimento pretendia fazer diversas pesquisas, trabalhos com intercâmbio - e à segurança financeira também. Estão sendo alcançadas [as expectativas], mas não em sua plenitude como eu desejava, diante das reais condições de nossa universidade (PE2).

As expectativas positivas sobre o trabalho docente podem ser agentes motivadores da função, facilitadoras das relações pessoais entre alunos e professores ou outros agentes envolvidos na organização, trazendo benefícios, inclusive, para o processo de ensino-aprendizagem. As instituições e os sujeitos que se preparam para lidar com essas expectativas e atendê-las ou para contornar as insuficiências de forma positiva terão melhor desempenho. De outra parte, quando essas expectativas são desconsideradas, os resultados prováveis incluem frustração, desgaste, estresse e perdas mútuas para docentes, discentes, instituições e sociedade (Witter, 2003).

\section{Qualidade de vida e saúde após a docência}

Os docentes relataram mudanças positivas em sua qualidade de vida e saúde, prioritariamente no aspecto socioeconômico, conforme se observam as expressões 'estabilidade financeira', as quais possibilitaram a aquisição de bens imóveis (para moradia própria) e bens de consumo, incluindo principalmente automóveis. Nesse aspecto, apenas um docente relatou ter sofrido perda salarial ao vir trabalhar na universidade; entretanto, revelou expectativa de melhorar a situação à medida que venha a obter as titulações acadêmicas e receber os respectivos incentivos financeiros:

Com o ingresso na academia eu tive uma perda de rendimentos, pois as oportunidades dentro da secretaria de Saúde eram maiores, porém os ganhos em qualidade de vida superam. A partir da minha entrada no mestrado e agora no doutorado, abrem-se portas para uma melhor situação financeira (PSC2). 
Com o meu trabalho na universidade, foi possível adquirir minha residência, trocar de carro e manter um acesso melhor aos bens de consumo (PSC1).

Foi uma transformação benéfica, com significativa melhora no aspecto financeiro (PE1).

Alcancei minha casa própria e melhorei bastante a vida financeira (PE2).

Aumentou meu poder aquisitivo (PN).

Pude ter acesso a melhores condições financeiras (PEF).

Nos aspectos psicoemocionais de saúde física e qualidade de vida, apenas dois docentes relataram mudanças positivas relacionadas ao ingresso na carreira docente, como amadurecimento e experimentação de um ambiente de trabalho melhor que o anterior. Contudo, nessa questão, predominou o relato de sofrimento relacionado a pressões por produtividade no trabalho, uso excessivo da voz, conflitos interpessoais com outros professores e, em menor amplitude, com alunos, estresse, e sintomas cardiovasculares e psicoemocionais relacionados a ele, cansaço, dentre outros, conforme verificado nas falas:

A docência contribui para enfrentar todos os desafios interiores e me ensina a superar cada vez mais as dificuldades de relacionamento. (...) Percebo que como a voz é o nosso principal instrumento de trabalho, sinto-me um pouco fragilizada (PSCl).

A relação humana é sempre conflituosa. (...) Já tive momentos difíceis com professores. (...) Com a entrada na universidade, as pressões, comparadas com as do meu outro serviço, diminuíram (PSC2).

Pressão psicoemocional é em relação a minha própria pressão: sempre fui muito exigente comigo mesma e isso tem aumentado gradativamente. (...) A gente sabe que onde há relação humana há conflitos. (...) [A saúde] piorou bastante, já virei noites trabalhando, já tive taquicardia, tonturas, sinais de estresse mesmo, cansaço corporal (PE1).

Grande pressão psicológica para dar conta da carga horária excedente que ocasiona cansaço físico e mental (PE2).

Grandes pressões do trabalho. (...) Posso destacar o cansaço mental (PN). 
Em estudo sobre a percepção da qualidade de vida, realizado com docentes da área de saúde, Oliveira et al. (2012) identificaram nos relatos a expressão de "ausência de lazer com consequentes distúrbios do sono favorecendo doenças psíquicas; excesso de trabalho; comprometimento da interação social e familiar, com influência sobre a saúde e a qualidade de vida" (Oliveira et al., 2012, p. 741). O trabalho executado por essa categoria contribui para o adoecimento psicossocial e também físico, influenciando a vida familiar e todas as outras esferas de relacionamento, gerando perda da qualidade de vida.

De acordo com Cardoso et al. (2011), a relação entre os aspectos psicossociais do trabalho e repercussões físicas, tal como a dor musculoesquelética, tem sido estudada na função ocupacional docente. A comum sobrecarga de atividades, somada a aspectos psicossociais desfavoráveis do trabalho, pode fazer desenvolver/agravar quadros álgicos, principalmente nos membros superiores, inferiores e dorso. Ao utilizar um modelo de demanda psicológica do trabalho e controle sobre tarefas em relação aos trabalhos de alta exigência, ativo, passivo e de baixa exigência, encontrou-se associação com a ocorrência de queixas de dor musculoesquelética em especial para trabalho de alta exigência de professores, corroborando os achados do presente estudo no relato dos professores sobre sofrerem 'pressões' e acerca do sentimento de 'cansaço, esgotamento físico'.

Dentre as diversas vulnerabilidades de saúde que a experimentação cotidiana do estresse no ambiente de trabalho acarreta está a fadiga vocal. Professores com esse problema mostraram níveis mais elevados de estresse e ansiedade do que professores que não o apresentavam. Professores com transtornos mentais comuns (muitas vezes relacionados à experimentação do estresse) apresentaram quase seis vezes mais disfonia do que aqueles sem esses problemas, situação que, além de comprometer a qualidade de vida do profissional, interfere no processo de ensino-aprendizagem, no qual a comunicação pela voz é uma das principais ferramentas (Souza et al., 2011).

Quanto a modificações no aspecto espiritual, dentre outros aspectos de qualidade de vida e saúde, após o ingresso na carreira docente, os sujeitos apresentaram posicionamentos sintéticos e heterogêneos:

É difícil explicar, mas meu ingresso na universidade foi uma promessa que Deus cumpriu na minha vida e, sendo assim, isso trouxe mudanças na minha intimidade com o Senhor (PSCl).

Eu sou ateu. Isso para mim não trouxe mudança (PSC2).

Foi diminuído bastante o meu tempo com Deus (PEl). 
O tempo ficou escasso, mas sempre separo um momento para ir à igreja (PN).

Não houve mudanças (PEF).

A restrição entre os docentes ao tratar desse assunto evidencia que o espaço acadêmico ainda é permeado pela concorrência entre ciência e fé, e que, portanto, interfere nessa interface dos sujeitos. Entretanto, diversos estudos atestam que a fé pode ser um recurso importante para o manejo de problemas de saúde, inclusive aqueles psicoemocionais, não devendo ser negligenciada (Levin, 2001).

\section{A formação do sujeito profissional: o principal papel docente}

Para os docentes, o principal papel social desempenhado é a formação dos sujeitos acadêmicos, servindo de motivação para o exercício docente. As expressões e a voz utilizadas nos relatos, novamente, enfatizam o conceito tradicional de relação professor-aluno, posicionando o primeiro como principal responsável pela formação do segundo; não são mencionados processos de mediação ou facilitação, como mostram as falas a seguir:

Esse foi um ponto crucial que me trouxe a trabalhar na universidade. Então o que me motiva é esse papel social, de professor trabalhando coletivamente para orientar, ajudar esses novos profissionais (PSC2).

Temos uma responsabilidade muito grande para com a sociedade de formar bons profissionais, pessoas capacitadas que venham somar para a saúde da população, que venham de fato para servir. Percebo minha condição como orientadora e formadora desses profissionais, e contribuo para as devidas mudanças (PEl).

Tenho papel político e transformador, formando os futuros profissionais de nosso país, assim entendo essa ser minha maior responsabilidade, o 'ser docente' (PE2).

Meu papel social é de educador, de dar uma boa formação aos alunos para que eles retornem à sociedade em mudanças no campo da saúde que visem à melhoria de vida da população. Para mim a condição docente é de formadora (PN).

O meu maior papel e primordial é a formação dos acadêmicos, de sermos formadores de bons profissionais para o nosso sistema (PEF).

Apenas um docente menciona como aspectos da formação dos profissionais os componentes moral e ético: 
Em uma escala, coloco a condição de docente acima das demais profissões, (...) em relação à responsabilidade na formação de outros profissionais. (...) acredito que o meu papel social é um compromisso com o futuro profissional da comunidade universitária, colocando no mercado profissionais com competitividade, mas acima de tudo com conhecimento e compromisso ético e moral (PSC1).

Importa destacar que a formação profissional parte do entendimento de sujeitos inteiros, cujo componente de habilidades e conhecimentos técnico-profissionais deve articular-se com aqueles morais e éticos, especialmente em se tratando de profissionais de saúde. Garantir que os espaços de sala de aula e de prática acadêmica dos estudantes também sejam de reflexão-(re)construção moral e ética deve ser uma preocupação dos docentes. Na relação ensino-aprendizagem, o aluno não deve ocupar apenas o papel de receptor, mas de agente transformador, tendo grande importância seu envolvimento e senso crítico da formação, apesar de o professor, tradicionalmente, dominar essa relação (Witter, 2003).

Em estudo relativo à formação de profissionais de saúde, Carvalho et al. (2012) identificaram que diversos valores compõem o desenvolvimento moral e ético dessa formação, variando de acordo com o ano de estudo na graduação e, também, com o tipo de curso. O valor mais reportado pelos alunos dos cursos da área de saúde foi a responsabilidade. Os autores afirmam que o desenvolvimento de valores deve ser garantido durante a formação profissional em cursos nessa área.

\section{Melhorias na universidade podem impactar na qualidade do processo de ensino-aprendizagem e no processo de trabalho}

Na percepção dos docentes, são sugeridos, prioritariamente, investimentos estruturais (espaço físico de salas de aula, salas de professores, laboratórios e bibliotecas), contratação de novos servidores (visando à reposição das aposentadorias, exonerações e outas perdas de vagas, bem como para atender à expansão universitária que tem ocorrido por intermédio da ampliação do número de vagas discentes nos cursos existentes e criação de novos cursos) e qualificação dos recursos humanos existentes, especialmente do ponto de vista didático-pedagógico, considerando-se que, nos cursos de bacharelado, predominam como docentes profissionais também bacharéis:

Sabemos que o processo ensino-aprendizagem representa uma gama de ações, teóricas e práticas e que vão muito além do entendimento de profissionais oriundos de uma formação como a minha [bacharel]. Ao entrar na docência, senti necessidade de conhecimentos aplicados à área de licenciatura; fica a sugestão 
de capacitações dos docentes voltadas para a prática da docência [técnicas pedagógicas] e incentivo ao intercâmbio de informações entre docentes de outras regiões - não que essas ações não existam, mas são isoladas e não fazem parte da rotina da comunidade docente (PSCl).

Necessitamos, primordialmente, de infraestrutura na universidade. Existem cursos em que é obrigatória a existência de laboratórios químicos, biológicos e de saúde para o desenvolvimento do aluno, o que não acontece. Posteriormente a isso, investir em mestrados e doutorados para os docentes (PE2).

Os docentes sugerem, ainda, a realização de reformas administrativas que favoreçam a descentralização das decisões e a comunicação entre os setores:

A administração da universidade é muito fragmentada entre reitorias e centros: falta diálogo. Precisa promover seminários, discussão com a reitoria, outros professores e alunos. Falta um número correto de professores e servidores, assim o que falta é essa integração entre os níveis da universidade; ajustes físicos estruturais em materiais e equipamentos (PSC2).

Maior envolvimento entre os níveis da universidade, mais comunicação, assembleias; melhor organização nos processos em que existem vários encaminhamentos, no entanto, há muita demora e muitas vezes descaso com os mesmos; seria necessário um órgão de fiscalização desses setores; auditorias internas (PEl).

O que a Ifes necessita para melhorar o processo de ensino é: investimento na capacitação dos profissionais; estrutura física de salas e laboratórios; maior envolvimento entre os níveis da universidade, mais comunicação, assembleias; incentivo ao intercâmbio entre docentes de outras instituições (PN).

No tocante às sugestões dos docentes sobre as possibilidades de melhorias organizacionais e estruturais na Ifes que impactam tanto na qualidade de vida dos sujeitos quanto na qualidade do processo de ensino-aprendizagem vivenciada no processo de trabalho, é preciso considerar a necessidade de iniciativa e a governabilidade de cada sujeito envolvido. A esse respeito, González e Almeida (2008) afirmam o seguinte:

O conflito que inquieta o educador e que o faz refletir, é o mesmo que o transforma e o modifica. $\mathrm{O}$ avanço na construção de um novo paradigma no ensino-aprendizagem nasce do conflito trabalhado e superado. A adequação do plano idealizado à realidade vivenciada ocorre por meio do comprometimento dos envolvidos e os diferentes graus de poder e governabilidade (González e Almeida, 2008, p. 25). 


\section{Considerações finais}

A descrição da percepção da experiência do trabalho docente em cursos de saúde a partir de um panorama geral de aspectos do processo de ensino-aprendizagem utilizado, inter-relações, expectativas sobre a carreira profissional, concepções sobre o papel docente, facilidades e dificuldades experimentadas, bem como mudanças na qualidade de vida e saúde dos próprios sujeitos é pioneira no contexto da Ifes estudada.

A abordagem escolhida para coleta, processamento e análise de dados favoreceu o estudo das variáveis estabelecidas. Verificou-se que a estratégia de amostragem por conveniência, após convite aberto, foi insuficiente para a categoria de professores de Medicina, bem como para a generalização dos resultados. Entretanto, contribuiu para revelar a singularidade da condição docente experimentada pelos participantes do estudo.

Destacou-se entre os docentes a necessidade de abrir espaço para estratégias inovadoras, dinâmicas e ativas, as quais atendam melhor às necessidades do aluno contemporâneo e contribuam para a aprendizagem significativa. Essa deve ser uma iniciativa pessoal, institucional e social que requer muitas estruturas.

As relações interpessoais de docentes e alunos ou outros participantes das relações institucionais - tais como demais professores e técnicos administrativos - foram reconhecidas pelos professores como mediadoras da qualidade do processo de ensino-aprendizagem e da qualidade do processo de trabalho. Os professores problematizaram lacunas institucionais quanto a estrutura física, recursos humanos, aperfeiçoamento profissional, entre outras, que têm implicações para o processo de trabalho dentro da Ifes.

Os docentes reconhecem a importância social de sua atuação; entretanto, concentram-se em agir sobre o desenvolvimento de habilidades técnico-científicas dos alunos, contribuindo de forma escassa para a formação deles nos aspectos morais e éticos.

Ao se tratar de qualidade de vida e saúde, a maior parte dos docentes se sente vulnerável e desgastada, principalmente em aspectos psicossociais, o que influencia as suas relações dentro e fora do ambiente de trabalho, inclusive na família.

A percepção do trabalho docente apresentada neste estudo reflete uma realidade social marcada pela vinculação produtivista e exploradora, característica do mundo globalizado, em detrimento das adequadas condições estruturais, materiais e de recursos humanos que poderiam garantir melhor qualidade laboral e favorecer a saúde do trabalhador docente. Embora o exercício profissional tenha sido identificado em grande medida pelos participantes do estudo como fonte de estabilidade e realização pessoal e financeira, é necessário destacar a precariedade e a sobrecarga de trabalho, 
aspectos subestimados socialmente em grande medida pela visão de que são inerentes ao panorama funcional das instituições públicas de ensino superior.

Contudo, considerando que tais condições tendem a ser indutoras de sofrimento e adoecimento, entre outros aspectos, é de fundamental importância a reflexão dessa temática entre docentes, movimentos sindicais, órgãos de classe, instituições de ensino e sociedade, a fim de subsidiar ajustes institucionais, legais, curriculares e sociais que interfiram no processo de ensino-aprendizagem e qualidade de vida vivenciados pelos profissionais docentes.

Resumen Se buscó conocer la percepción de la experiencia del trabajo docente en cursos de salud de una universidad federal de la región Norte de Brasil. A partir de un enfoque cualitativo, fueron entrevistados seis profesores de cursos de salud de esa universidad, cuyos datos fueron sometidos al análisis de contenido. Predominaron las mujeres en la función docente, y la valoración de esta función como vínculo laboral estable, fuente de ingresos y función social. En el trabajo docente, la mayoría se concentra en el desarrollo de habilidades técnicas y científicas de los estudiantes, lo que expresa la necesidad de la formación continua y un apoyo institucional insuficiente. Las relaciones personales de estos profesores con alumnos y otros docentes y con técnicos administrativos, son reconocidamente mediadoras de la calidad en el proceso de enseñanza-aprendizaje y trabajo. En relación a la salud, la mayoría se siente vulnerable y desgastada, sobre todo en los aspectos psicoemocionales, lo que influye en sus relaciones sociales dentro y fuera del ambiente de trabajo. Aunque la práctica profesional se haya identificado como una fuente de estabilidad, realización personal y financiera, sobresalen la precariedad y la sobrecarga de trabajo, que tienden a provocar sufrimiento y enfermedad. Esta reflexión entre los docentes, los movimientos sindicales y las instituciones educativas puede sustentar ajustes institucionales, legales, curriculares y sociales para mejorar el proceso de enseñanza-aprendizaje y la calidad de vida de los docentes.

Palabras clave docente; salud del trabajador; recursos humanos en salud. 


\section{Notas}

1 Universidade Federal do Acre, Rio Branco, Acre, Brasil.

Doutoranda em Saúde Pública pela Universidade de São Paulo.

$<$ rozilainee@gmail.com>

Correspondência: Universidade Federal do Acre, Campus Universitário, BR 364,

Km 4, Distrito Industrial, CCSD, sala 211 ( $1^{\circ}$ andar), Caixa Postal 500, CEP 69920-900,

Rio Branco, Acre, Brasil.

2 Ministério da Saúde, Departamento de Atenção Básica, Brasília, Distrito Federal, Brasil.

Especialização em Saúde Coletiva e Educação na Saúde (em andamento) pela Universidade Federal do Rio Grande do Sul.

$<$ brunacunha_19@hotmail.com>

3 Universidade Federal do Acre, Rio Branco, Acre, Brasil.

Doutoranda em Saúde Pública pela Escola Nacional de Saúde Pública Sergio Arouca, Fundação Oswaldo Cruz.

$<$ fernandacomjesus@homail.com>

\section{Referências}

ALVES, Marcia G. de M. et. al. Estresse no trabalho e hipertensão arterial em mulheres no Estudo Pró-Saúde. Revista de Saúde Pública, São Paulo, v. 43, n. 5, p. 893-896, 2009.

BARRETO, Ivete S. Programas de atenção à saúde mental dos trabalhadores das instituições federais de ensino superior. Revista Eletrônica de Enfermagem, Goiânia, v. 10, n. 3, p. 862-863, 2008. Disponível em: <www.fen. ufg.br/fen_revista/v10/n3/pdf/v10n3a35. pdf $>$. Acesso em: 23 jan. 2015.

BATISTA, Nildo et. al. O enfoque problematizador na formação de profissionais da saúde. Revista de Saúde Pública, São Paulo, v. 39, n. 2, p. 231-237, 2005.

BORSOI, Isabel C. F. Trabalho e produtivismo: saúde e modo de vida de docentes de instituições públicas de ensino superior. Cadernos de Psicologia Social do Trabalho, São Paulo, v. 15, n. 1, p. 81-100, 2012.
BRUM, Liliani M. et al. Qualidade de vida dos professores da área de ciências em escola pública no Rio Grande do Sul. Trabalho, Educação e Saúde, Rio de Janeiro, v. 10, n. 1, p. 125-145, 2012.

CAMPOS, Gastão W. S. et al. Tratado de saúde coletiva. São Paulo: Hucitec; Rio de Janeiro: Editora Fiocruz, 2006.

CARDOSO, Jefferson P. et al. Aspectos psicossociais do trabalho e dor musculoesquelética em professores. Cadernos de Saúde Pública, Rio de Janeiro, v. 27, n. 8, p. 1.498-1.506, 2011.

CAREGNATO, Rita A. C.; MUTTI, Regina. Pesquisa qualitativa: análise de discurso versus análise de conteúdo. Texto \& Contexto Enfermagem, Florianópolis, v. 15, n. 4, p. 679-684, out.-dez. 2006.

CARVALHO, Amâncio A. S.; CARVALHO, Graça S.; RODRIGUES, Vitor M. C. P. Valo- 
res na educação em saúde e a formação profissional. Trabalho, Educação e Saúde, Rio de Janeiro, v. 10, n. 3, p. 527-540, 2012. Disponível em: < www.scielo.br/pdf/tes/v10n3/ al0v10n3.pdf>. Acesso em: 2 dez. 2012.

COTTA, Rosangela M. M. et al. Construção de portfólios coletivos em currículos tradicionais: uma proposta inovadora de ensino-aprendizagem. Ciência \& Saúde Coletiva, Rio de Janeiro, v. 17, n. 3, p. 787-796, 2012.

CRESWELL, John W. Projeto de pesquisa: métodos qualitativo, quantitativo e misto. 2. ed. Porto Alegre: Artmed, 2007.

DURAN, Marilia C. G. Repensar a docência e definições políticas no campo. Cadernos de Pesquisa, São Paulo, v. 38, n. 135, p. 841844, 2008.

GASPARINI, Sandra M.; BARRETO, Sandhi M.; ASSUNÇÃO, Ada Á. O professor, as condições de trabalho e os efeitos sobre sua saúde. Educação e Pesquisa, São Paulo, v. 31, n. 2, p. 189-199, 2005.

GONZÁLEZ, Alberto D.; ALMEIDA, Marcio J. Onde nascem e como se concretizam as mudanças na formação superior da área da saúde? Espaço para a Saúde, Londrina, v. 10, n. 1, p. 25-33, dez. 2008.

LEVIN, Jeff. Deus, fé e saúde: explorando a conexão espiritualidade-cura. São Paulo: Pensamento Cultrix, 2001.

MACEDO, Luis E. T. de et. al. Estresse no trabalho e interrupção de atividades habituais, por problemas de saúde, no Estudo Pró-Saúde. Cadernos de Saúde Pública, Rio de Janeiro, v. 23, n. 10, p. 2.327-2.336, 2007.

OLIVEIRA, Elizabete R. A. et al. Gênero e qualidade de vida percebida: estudo com professores da área de saúde. Ciência \& Saúde Coletiva, Rio de Janeiro, v. 17, n. 3, p. 741747, 2012.

ORGANIZACIÓN MUNDIAL DE LA SALUD (OMS). Informe sobre la salud en el mundo - 2006: Colaboremos por la salud.
Genebra: OMS, 2006. Disponível em: <www. who.int/whr/2006/whr06_es.pdf >. Acesso em: 3 maio 2011.

PAIVA, Mirella L. M. F.; DEL PRETTE, Zilda A. P. Crenças docentes e implicações para o processo de ensino-aprendizagem. Psicologia Escolar e Educacional, Campinas, v. 13, n. 1, p. 75-85, jan.-jun. 2009.

ROZENDO, Célia A. et al. Uma análise das práticas docentes de professores universitários da área de saúde. Revista Latino-Americana de Enfermagem, Ribeirão Preto, v. 7, n. 2, p. 15-23, 1999.

SGARIBOLDI, Aline R.; PUGGINA, Ana C. G.; SILVA, Maria J. P. Análise da percepção dos professores em relação aos sentimentos dos alunos em sala de aula. Revista da Escola de Enfermagem da USP, São Paulo, v. 45, n. 5, p. 1.206-1.212, 2011.

SINDICATO NACIONAL DOS DOCENTES DAS INSTITUIÇÕES DE ENSINO SUPERIOR (ANDES-SN). Não dá para esperar bons tempos, é hora de ir à luta. InforANDES: Informativo Especial Setor das IFES, Brasília, maio 2012.

SOUZA, Carla. L. et al. Fatores associados a patologias de pregas vocais em professores. Revista de Saúde Pública, São Paulo, v. 45, n. 5, p. 914-921, 2011.

SOUZA, Kátia R.; BRITO, Jussara C. Sindicalismo, condições de trabalho e saúde: a perspectiva dos profissionais da educação do Rio de Janeiro. Ciência \& Saúde Coletiva, Rio de Janeiro, v. 17, n. 2, fev. 2012.

TEIXEIRA, Inês A. C. Da condição docente: primeiras aproximações teóricas. Educação \& Sociedade, Campinas, v. 28, n. 99, p. 426-443, 2007.

THEOREL, T. Working Conditions and Health. In: BERKMAN, Lisa; KAWACHI, Ichiro (Org.). Social Epidemiology. Nova York: Oxford University Press, 2000. p. 95-117

TORRES, Patricia L.; ALCANTARA, Paulo R.; IRALA, Esrom A. F. Grupos de consenso: 
uma proposta de aprendizagem colaborativa para o processo de ensino-aprendizagem. Revista Diálogo Educacional, Curitiba, v. 4, n. 13, p. 129-145, 2004.

VEDOVATO, Tatiana G.; MONTEIRO, Maria I. Perfil sociodemográfico e condições de saúde e trabalho dos professores de nove escolas estaduais paulistas. Revista da Escola de Enfermagem da USP, São Paulo, v. 42, n. 2, p. 290-297, 2008.

WITTER, Geraldina P. Professor-estresse: análise de produção científica. Psicologia Escolar e Educacional, Campinas, v. 7, n. 1, p. 33-46, 2003.
WORLD HEALTH ORGANIZATION (WHO). Health Impact of Psychosocial Hazards at Work: An Overview. Genebra: WHO, 2010. Disponível em: <http://whqlibdoc.who.int/ publications/2010/9789241500272_eng.pdf>. Acesso em: 2 maio 2011.

ZARAGOZA, José M. E. O mal-estar docente: a sala de aula e a saúde dos professores. 3. ed. Bauru: Edusc, 1999.

Recebido em 05/02/2013

Aprovado em 12/05/2014 